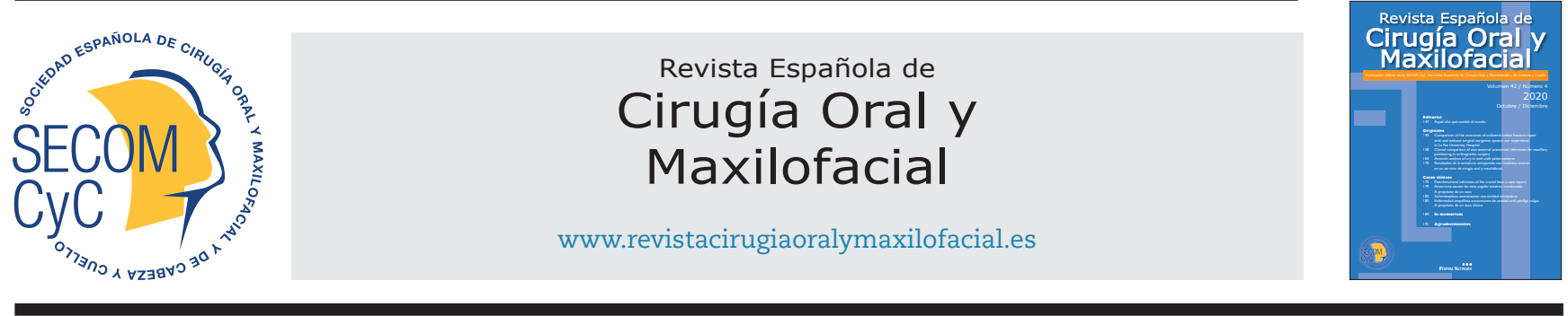

\title{
Original
}

\section{Acoustic analysis of cry in with cleft palate patients}

\section{Bricelys Pulgar, Dionelys Barazarte, Andrea Maldonado, Jésus Pérez, José Golaszewski y Rubén Muñoz}

Oral and maxilofacial Surgery, "Dr. Angel Larralde” University Hospital, Carabobo University. Naguanagua, Venezuela

\section{INFORMACIÓN DEL ARTÍCULO}

Historia del artículo:

Recibido: 4 de mayo de 2020

Aceptado: 15 de junio de 2020

\section{Keywords:}

Cleft palate, crying, acoustic analysis.

\begin{abstract}
A B S T R A C T
Introduction: Crying in newborns and infants is a functional expression of biological interest. Through, acoustic analysis of crying, results of a primary palatoplasty can be evaluated in patients with cleft palate before development of speech, is objective, non-invasive, quick and simple tool for vocal exploration. The objective is to determine Fundamental Frequency (F0) of spontaneous crying in patients with pre and postoperative cleft palate, and compare with healthy control group through PRAAT software, in period between 2017 and 2019.

Materials and methods: A sample of 16 patients from 18 to 30 months of age with cleft palate was obtained. Recordings were made of spontaneous pre and postoperative crying, and healthy control group; later were digitally recorded, and analyzed through PRAAT Software. Results: $56.2 \%$ were female and $43.7 \%$ were male, witn average age of 25.8 months. Primary palatoplasty was performed using Veau Wadrill technique and Furlow technique. F0 of crying was Pitch average value $349.125 \mathrm{~Hz}$ preoperative and Pitch average postoperative control $369.775 \mathrm{~Hz}$. More acute crying emissions were observed in postoperative period $(\mathrm{p}<0.000)$, presenting similar values with control group $(\mathrm{p}<0.000)$.

Conclusion: Fundamental frequency (FO) was determined in patients with cleft palate, they presented a significant increase of $15,5 \%$ in postoperative controls of primary palatoplasty, similar to healthy control group.
\end{abstract}

\footnotetext{
*Autor para correspondencia:

Correo electrónico: bricelysp@gmail.com (Bricelys Pulgar).
}

DOI: 10.20986/recom.2020.1154/2020

1130-0558/@ 2020 SECOM. Publicado por Inspira Network. Este es un artículo Open Access bajo la licencia CC BY-NC-ND (http:// creativecommons.org/licenses/by-nc-nd/4.0/). 


\section{Análisis acústico del llanto en pacientes con hendidura palatina}

\section{R E S U M E N}

Palabras clave:

Hendidura palatina, llanto, análisis acústico.
Introducción: El llanto de los recién nacidos y lactantes es una expresión funcional de interés biológico, por lo cual, a través del análisis acústico del llanto se pueden evaluar los resultados de una palatoplastia primaria en pacientes con hendidura palatina antes del desarrollo del habla, por ser una herramienta objetiva, no invasiva, rápida y sencilla de exploración vocal. El objetivo es determinar la frecuencia fundamental (F0) del llanto espontáneo en los pacientes con hendidura palatina pre y posoperatorio, y comparar con el grupo control sano a través del software PRAAT, en el periodo entre el año 2017 y 2019.

Materiales y métodos: Se obtuvo una muestra de 16 pacientes de 18 a 30 meses de edad con hendidura palatina. Se realizaron grabaciones del llanto espontáneo pre y posoperatorio, y del grupo control sano; posteriormente fueron grabadas digitalmente, y analizadas a través del software PRAAT. Resultados: El 56,2 \% fue del género femenino y el 43,7 \% del género masculino, con edad promedio de 25,8 meses. Se realizó palatoplastia primaria mediante técnica de Veau Wadrill y técnica Furlow. La F0 del llanto fue de valor promedio Pitch $349.125 \mathrm{~Hz}$ preoperatorio y un control posoperatorio promedio Pitch $369.775 \mathrm{~Hz}$. Se evidenció emisiones del llanto más agudas en el posoperatorio $(p<0,000)$, presentando valores similares con el grupo control $(p<0,000)$. Conclusión: Se determinó frecuencia fundamental (F0) en los pacientes con hendidura palatina, presentaron un incremento significativo de 15,5\% en los controles posoperatorio de palatoplastia primaria, similares al grupo control sano.

\section{INTRODUCTION}

Cleft lip palate is most common congenital anomalies in the craniofacial region, with higher prevalence of births than neural tube defects or Down syndrome, according to WHO. Although causal factors are unknown, multifactorial etiology with genetic predisposition and environmental influence is currently accepted ${ }^{1,2}$. Multidisciplinary management of patients with cleft lip palate is of most importance their future psychosocial development. Inability communicates affects psychological and emotional well-being children and their families ${ }^{3}$. However, patients with cleft palate present anatomical alterations due to lack of fusion of palatal processes during pregnancy, therefore, there is a risk distortion of resonance and articulation of sounds, interfering speech same $e^{4}$.

Crying of newborns and infants is functional expression of fundamental biological interest, such as hunger, cold, pain, loneliness, and even joy ${ }^{5,6}$. Characteristics of crying reflect development and possibly integrity of central nervous system, is complex phenomenon that involves the production of sound the vocal cords and occurs fundamentally during expiratory phase of breathing; requires functioning of respiratory, laryngeal and supralaryngeal muscles, therefore, is under control of neurovegetative regulation systems of brain stem, especially vagal complex includes the cranial nerves IX to XII'. Therefore, analysis of infant crying is suitable complementary tools detecting certain pathologies such as neonatal hypoxia?.

Due advancement of technology, software has been created for acoustic analysis of voice and crying, functioning as an objective, non-invasive, quick and simple tool vocal exploration, analyzing acoustic signals obtained from a sound emission or crying'. The most widely used program is PRAAT software, originally designed for instrumental phonetics, but has great capabilities for acoustic signal analysis and spec- trography. This software has been used for acoustic analysis of pathological voices ${ }^{10}$.

PRAAT is computer program analyzing, synthesizing, and manipulating vocal sounds, record a sound with any other audio input device, or audio file. It was developed since 1992 by Paul Boersma and David Weenink at Institute of Phonetic Sciences at University of Amsterdam. There are versions for most common operating systems: Macintosh, Windows, Linux ${ }^{11}$. It has been possible identify irregularities present during crying episode, such as abrupt variations in tone ${ }^{12}$.

Acoustic analysis of crying, can analyze fundamental frequency (FO), it is frequency with which vocal cords vibrate during production of sounds originating from vocal cords and measured in $\mathrm{Hz}^{13}$. It has been suggested fundamental frequency ( $\mathrm{F} 0$ ) crying in 4-month-old infants can predict F0 speech expressions after 5 years of age ${ }^{14}$. However, acoustic characteristics of crying are directly influenced by child's physical and psychological state or by external factors. Differences in F0 of crying have been determined in patients with brain damage, cleft palate, hydrocephalus, sudden infant death syndrome and many other diseases ${ }^{15}$.

Due to anatomical alterations in vocal tract presented by patient with a cleft palate, pronunciation of the first words can be produced at 2 years of age. Due crying emissions can be obtained in accessible way during preoperative evaluation, following objective is proposed: to determine fundamental frequency (FO) of spontaneous crying in patients with pre and postoperative cleft palate, and compare results with healthy control group with PRAAT software.

\section{MATERIALS AND METHODS}

A population of 21 patients with cleft palate was obtained, who attended Oral and Maxillofacial Surgery Service "Dr. 
Atilio Perdomo" of University Hospital "Dr. Ángel Larralde” in Valencia-Venezuela, in period between January 2017 November 2019; study was approved by University of Carabobo and "Dr. Ángel Larralde" University Hospital, all representatives of patients signed an informed consent agreement (Approval of Committee on Bioethics and Human Research No. 16-1225).

A sample 16 patients was obtained, who met following inclusion criteria:

1. Patient with a diagnosis of cleft palate with a history of cheiloplasty.

2. Patients with isolated secondary cleft palate.

3. Age between 18 months to 30 months.

4. Informed consent.

5. Patient without associated systemic changes.

6. Study of normal audiometry.

7. Compliance with postoperative controls.

The type of cleft palate was determined by Veau's classification. Patients who did not meet aforementioned criteria were excluded. Control group from 10 patients, grouped by gender. Study protocol to be carried out was explained to representatives, informing is of voluntary participation complying with informed consent, as well as a clinical evaluation to rule out present pathologies or systemic alterations.

In the study, representatives of patient and control group were in a room without sonic contamination; study was explained, to filled the medical record, where recording of participant's spontaneous cry was approximately 60 seconds, recorded digitally on a VIT M2400 laptop with Realtek High Definition audio 6.0.1.6029 microphone. Distance from mouth microphone was $10 \mathrm{~cm}$, spontaneous crying emissions were analyzed with PRAAT Software Voice Report version 4.6.06. Audios with background noise were excluded.

Patients with cleft palate, complementary studies were carried out with preoperative protocol, later, underwent surgical intervention where primary palatoplasty was performed, patients underwent surgery by same surgeon, and postoperative control was verified, which was maintained without complications. Recordings were made in 3 stages in the patients: preoperative and late postoperative in 6 months, and then results are compared with control group (Figures 1 and 2).

SPSS version 19.0 (IBM SPSS Statistics) was used perform all statistical analyzes. Through, dependent variants, FO of spontaneous crying changes in patients with cleft palate are evaluated with their preoperative and postoperative control at 6 months, and are subsequently compared with control group. Independent variant tests were performed to assess relationship F0 to gender.

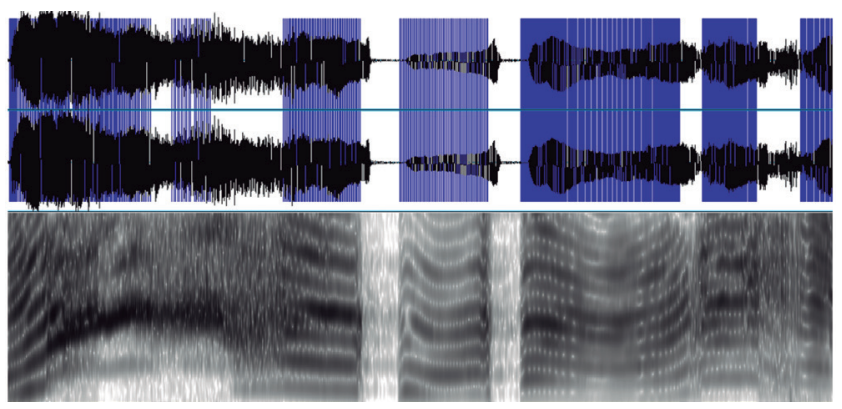

Figure 1. Acoustic analysis of spontaneous crying in patients with cleft palate in preoperative control.

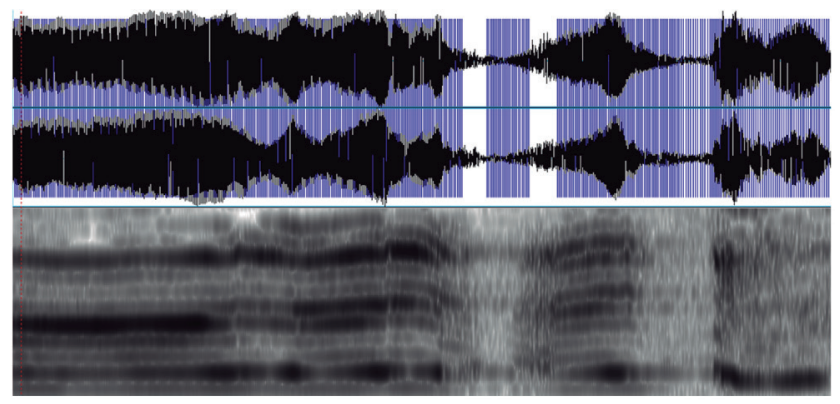

Figure 2. Acoustic analysis of spontaneous crying in patients with cleft palate in postoperative control at 6 months.

\section{RESULTS}

A $56.3 \%(n=9)$ was obtained in female and $43.8 \%$ $(n=7)$ for male, representing an average age of 25.8 months (DV $=3.98)$. Regarding primary palatoplasty surgical procedure, using Veau Wadrill technique $(n=5)$, Furlow technique $(n=3)$, and combination of both primary palatopasty techniques ( $\mathrm{n}=8$ ), being the most frequent with $50 \%$, no sequelae were observed during postoperative control. Table I shows relationship of type of cleft palate by Veau's classification with surgical technique used.

A total of 52 spontaneous crying recordings were analyzed, divided by preoperative, postoperative and control group audio. Used PRAAT software, it was determined duration of spontaneous crying episode was 2.13 seconds in patients with cleft palate (DV $=0.76)$, compared to control group, was 2,7 seconds (DV $=0.66)$. Regarding fundamental

Table I. Relation of type of cleft palate by Veau's classification, and used primary palatoplasty technique

\begin{tabular}{|c|c|c|c|c|c|c|}
\hline \multirow{2}{*}{ Primary palatoplasty technique. } & \multirow{2}{*}{$\mathrm{n}$} & \multicolumn{4}{|c|}{ Type of palatal cleft by Veau's classification } & \multirow{2}{*}{$\%$} \\
\hline & & V1 & V2 & V3 & V4 & \\
\hline Veau Wardill technique & 05 & - & 03 & 02 & - & 31.2 \\
\hline Furlow technique & 03 & 03 & - & - & - & 18.7 \\
\hline Veau Wardill + Furlow technique & 08 & - & 01 & 05 & 02 & 50.0 \\
\hline
\end{tabular}


frequency (F0) of spontaneous crying, preoperative average Pitch value of $349.125 \mathrm{~Hz}$ (DV = 35,335) was obtained. Subsequently, in postoperative control average Pitch $369.775 \mathrm{~Hz}$ (DV $=41,387)$ was obtained, evidencing significant results with an increase in F0 postoperative control of spontaneous crying, reporting more acute type crying emissions $(p<0.000)$ represented in Table II. Compared with control group, average FO of spontaneous crying Pitch value of $437.103 \mathrm{~Hz}$ (DV = 38,170) was obtained, presenting similar values with postoperative group ( $p<0.000)$, represented Table III. In addition, no significant differences were reported between FO and gender ( $p>0.383$ ).

\section{DISCUSSION}

In this study, fundamental frequency (F0) of spontaneous crying in patients with cleft palate was determined through acoustic analysis. From results of study, a comparison was made with control group, determining difference between them. Statistical analyzes were performed to compare significant difference between clinical group and the control group.

Regarding results, there were no differences in results of F0 of crying with respect to gender, presenting similar values in the investigations carried out by Reby et al. ${ }^{16}$, Lee et $\mathrm{al}^{17}$. Furthermore, gender patterns of F0 appear from 11 years of age $^{17}$. Therefore, data for both genders were pooled in study.

Regarding surgical procedure, Gart \& Gosain recommends an evaluation at 3 months after surgical procedure in patients to rule out velopharyngeal insufficiency ${ }^{18}$; Because alteration can occur in $5 \%$ to $35 \%$ after a primary palatoplasty, reported by Yamaguchi ${ }^{19}$. However, there are acoustic findings in patients with velopharyngeal insufficiency, which may have low F0 values, established in evaluation of the voice ${ }^{20}$. In the study, no late postoperative sequelae were evidenced; this may be related early and timely surgical resolution in patients.

Fundamental frequency (F0) was also analyzed, showing more acute spontaneous crying emissions in postoperative control. These data are in agreement with results established by Wermker et al, reporting differences in spontaneous crying parameters (FO and PPQ (Tone Disturbance Ratio) between patients with cleft lip palate and healthy control group ${ }^{21}$. F0 medians of healthy control group of the study presented the ranges established in previous publications ${ }^{22}$. Research normal range of F0 during crying is reported, this depends on situations such as pain, hunger, irritation, among others ${ }^{23,24}$. But, Rothgänger in 2003 suggests that range decreases as the infant grows ${ }^{25}$.

Few studies have been found report use of acoustic analysis of crying in patients with cleft palate, compared pre and postoperative control through primary palatoplasty. With these data, early detection of alterations present in vocal tract can be carried out in patients with cleft palate in the postoperative period, avoiding the abnormal development of language and speech. Updating these data will help the scientific community to guide future research. Therefore, informing about changes present in FO of pre and postoperative crying, will help choose treatment in a timely manner in patients with cleft palate. It is important to highlight, to results obtained in this study are predictive data regarding vocal development of patient. For this reason, we recommend long-term follow-up of the patients, once the vocal language has been established in them, to evaluate verbal and progressive development of same; through studies such as acoustic analysis of voice. If vocal changes appear during follow-up, a careful examination should be performed to rule out abnormalities such as velopharyngeal insufficiency.

\section{CONCLUSION}

Fundamental frequency (F0) of spontaneous crying in patients with cleft palate presented an increase of $15.5 \%$ in postoperative controls, compared to control group. In addition, there were no significant differences with respect surgical technique used; therefore, performing an early and timely surgical resolution would avoid sequelae during development of speech. It should be noted acoustic analysis of crying is quick, simple and non-invasive procedure; being a complementary tool for evaluation of postoperative control of primary palatoplasty. The evaluation of patients with cleft palate must be carried out in a multidisciplinary way, returning function not only of swallowing but also of speech.

\section{Table II. FO of spontaneous crying in patients with cleft palate in the control preoperative and postoperative} at 6 months ago.

\begin{tabular}{|c|c|c|c|c|c|}
\hline & F0 Mean (Hz) & $\mathrm{Sd}$ & $\mathrm{T}$ & $\mathrm{Gl}$ & P-value \\
\hline Preoperative Control & 349,125 & 35,335 & & & \\
\hline $\begin{array}{l}\text { Postoperative } \\
\text { Control }\end{array}$ & 369,775 & 41,387 & $-5,927$ & 15 & 0,000 \\
\hline
\end{tabular}

Table III. Relation FO of spontaneous crying in patients with cleft palate in control postoperative, compared healthy control group $(p<0.000)$.

\begin{tabular}{|c|c|c|c|c|c|}
\hline & $\mathrm{N}$ & F0 Mean (Hz) & $\mathrm{Sd}$ & $\mathrm{t}$ & P-value \\
\hline Postoperative Control & 16 & 369,775 & 41,387 & 26,474 & \multirow{2}{*}{0,000} \\
\hline Healthy control group & 10 & 438,103 & 38,170 & 36,296 & \\
\hline
\end{tabular}




\section{R E F E R E N C E S}

1. World Health Organization. Oral health [Internet]. Fact sheet. 2012;318. Disponible en: https://www.who.int/news-room/ fact-sheets/detail/oral-health

2. Mossey PA, Little J, Munger RG, Dixon MJ, Shaw WC. Cleft lip and palate. Lancet. 2009;374(9703):1773-85. DOI: 10.1016/S01406736(09)60695-4.

3. Ruben RJ. Valedictory-why pediatric otorhinolaryngology is important. Int J Pediatr Otorhinolaryngol. 2003;67(suppl 1):S53S61. DOI:10.1016/j.ijporl.2003.09.001.

4. Morris H, Ozanne A. Phonetic, Phonological, and Language Skills of Children with a Cleft Palate. Cleft Palate Craniofacl J. 2003;40(5):460-70. DOI: 10.1597/1545-1569_2003_040_0460_ ppalso_2.0.co_2.

5. Michelsson K, Michelsson O. Phonation in the newborn, infant cry. Int J Pediatr Otorhinolaryngol. 1999;49(1):S297-S30. DOI: 10.1016/s0165-5876(99)00180-9.

6. Blanchard RJ, Blanchard DC, Rodgers J, Weiss SM. The characterization and modelling of antipredator defensive behavior. Neurosci Biobehav Rev 1990;14(4):463-72. DOI: 10.1016/s01497634(05)80069-7.

7. M Abnormal brain-stem function (brain-stem auditory evoked response) correlates with acoustic cry features in term infants with hyperbilirubinemia. J Pediatr. 1989;115(2):303-8. DOI: 10.1016/s0022-3476(89)80090-3.

8. Orozco García J, Reyes García C. Acoustic features analysis for recognition of normal and hypoacustic infant cry based on neural networks. Artificial Neural Nets Problem Solving Methods. 2003; 615-22. DOI: 10.1007/3-540-44869-1_78.

9. Mendes A, Ferreira L, Castro E. Software e hardware de análise acústica da voz e da fala. Distúrb común. 2012;24(3):421-30.

10. Núñez Batalla F, González Márquez R, Peláez González MB, González Laborda I, Fernández Fernández M, Morato Galán M. Acoustic Voice Analysis Using the Praat programme: Comparative Study With the Dr. Speech Programme. Acta Otorrinolaringologica (English Edition). 2014;65(3):170-6. DOI: 10.1016/j.otoeng.2014.05.007.

11. Boersma P, Heuven V. Speak and unSpeak with PRAAT. Glot International 2001;5(9/10):341-7.

12. Owren MJ. GSU Praat Tools: Scripts for modifying and analyzing sounds using Praat acoustics software. Behavior Research Methods. 2008;40(3):822-9. DOI: 10.3758/brm.40.3.822

13. Lopes L, Cunha Costa S, Costa W, Correia S. Acoustic assessment of the voices of children using nonlinear analysis: pro- posal for assessment and vocal monitoring. J. Voice. 2014;28(5): 565-73. DOI: 10.1016/j.jvoice.2014.02.013.

14. Levrero F, Mathevon N, Pisanski K, Gustafsson E, Reby D. The pitch of babies' cries predicts their voice pitch at age 5 . Biol. Lett. 2018;14:20180065. DOI: 0.1098/rsbl.2018.0065.

15. Michelsson K, Michelsson O. Phonation in the newborn, infant cry. International Journal of Pediatric Otorhinolaryngology. 1999;49(Suppl. 1);S297-S301. DOI: 10.1016/S0165-5876(99)00180-9.

16. Reby D, Levre'ro F, Gustafsson E, Mathevon N. Sex stereotypes influence adults' perception of babies' cries. BMC Psychol. 2016;4(1):19. DOI: 10.1186/s40359-016-0123-6.

17. Lee S, Potamianos A, Narayanan S. Acoustics of children's speech: developmental changes of temporal and spectral parameters. J Acoust Soc Am. 1999;105(3):1455-68. DOI: 10.1121/ 1.426686.

18. Gart MS, Gosain AK. Surgical Management of Velopharyngeal Insufficiency. Clin Plast Surg. 2014;41(2):253-70. DOI: 10.1016/j. cps.2013.12.010.

19. Yamaguchi K, Lonic DA. Treatment Protocol for Velopharyngeal Insufficiency and the Outcome. Plast Reconstr Surg. 2016;138(2):290e-299e. DOI: 10.1097/PRS.0000000000002386.

20. Villafuerte-Gonzalez R, Valadez-Jimenez VM, HernándezLópez X, Ysunza PA. Acoustic analysis of voice in children with cleft palate and velopharyngeal insufficiency. Int J Pediatr Otorhinolaryngol. 2015;79(7):1073-6. DOI:10.1016/j. ijporl.2015.04.030

21. Wermke K, Hauser C, Komposch G, Stellzig A. Spectral analysis of prespeech sounds (spontaneous cries) in infants with unilateral cleft lip and palate (UCLP): a pilot study. Cleft Palate Craniofac J. 2002;39(3):285-94. DOI: 10.1597/1545-1569_2002_ 039_0285_saopss_2.0.co_2.

22. Wasz-Hockert O, lind J, Vuorenkoski V, et al. The infant cry. A spectrographic and Auditory Analysis. London: William Heinemann Medical Books, ltd.; 1968. DOI: 10.106/0022510X(70)90194-2.

23. Chittora A, Patil HA. Data Collection of Infant Cries for Research and Analysis. J Voice. 2017;31(2):252.e15-252.e26. DOI: 10.1016/j.jvoice.2016.07.007.

24. Mandujano-Valdésa MA, Arch-Tiradob E, Verduzcob A, ReyesGarcíac CA, Pereira Fernándezd LP, Sánchez-Pérez C. Lo normal y lo anormal en el llanto del neonato y del infante. Ciencias Clínicas. 2013;14(1):12-20.

25. Rothgänger $\mathrm{H}$. Analysis of the sounds of the child in the first year of age and a comparison to the language. Early Human Development. 2003;75(1-2):55-69. DOI: 10.1016/j.earlhumdev.2003.09.003. 